\title{
Developing micro-/nanoparticulate drug delivery systems using "design of experiments"
}

\author{
Bhupinder Singh, Rahul Bhatowa, Chandra Bhushan Tripathi, Rishi Kapil \\ University Institute of Pharmaceutical Sciences, Panjab University, Chandigarh, India.
}

\begin{abstract}
Of late, micro and nanoparticluate drug delivery systems have been gaining immense importance primarily attributed to their improved drug release controlling and targeting efficiencies. Also, the small particle size and desirable surface charge associated with these delivery systems render them suitable for specific applications like lymphatic uptake, pulmonary uptake, tumor targeting, brain targeting, etc. For decades, micro and nanoparticulate systems have been prepared by the conventional "trial and error" approach of changing One Variable at a Time (OVAT). Using this methodology, the solution of a specific problematic formulation characteristic can certainly be achieved, but attainment of the true optimal composition is never guaranteed. Thus, the present manuscript provides an updated account of the systematic approach "Design of Experiments (DoE)" as applicable to formulation development of microparticles and nanostructured systems. Besides providing a bird's eye view of the various experimental designs and optimization techniques employed for DoE optimization of such systems, the present manuscript also presents a copilation of the major micro/nano-structuctred systems optimized through DoE till date. In a nutshell, the article will act both as a ready reckoner of DoE optimization of micro/nano drug delivery systems and a catalyst in providing an impetus to young pharmaceutical "nano \& micro" researchers to venture into the rewarding field of systematic DoE optimization.
\end{abstract}

Key words: Contour plots, microparticles, nanoparticles, optimization, response surface

\section{INTRODUCTION}

The concept of drug delivery has undergone a paradigm shift today from the erstwhile concept of "right medicine" to that of "right medicine" at the "right (target) site" at the "right time." Therapeutic treatment now, thus, aims at better efficacy through the delivery of drugs in a sustained and site-specific manner. With these technological inventions of the controlled and targeted drug delivery, the traditional tablet and liquid oral formulations have been metamorphosed into the novel drug delivery systems (DDS), including micro/nanoparticulate DDS (MiNaDDS). Several types of MiNaDDS, including microcapsules, microspheres, nanoparticles (polymeric as well as lipidic), vesicular systems,

\section{Address for correspondence:}

Prof. (Dr.) Bhupinder Singh Bhoop,

University Institute of Pharmaceutical Sciences,

Panjab University, Chandigarh - 160 014, India.

E-mail: bsbhoop@yahoo.com

\begin{tabular}{|l|l|}
\hline \multicolumn{2}{|c|}{ Access this article online } \\
\hline Quick Response Code: & Website: \\
\hline & www.jpionline.org \\
\cline { 2 - 3 } & \\
\hline & \\
\hline
\end{tabular}

and self-emulsifying systems have been employed extensively owing to their paramount advantages over the unit dosage forms. These advantages comprise the reduced risk of systemic toxicity and local irritation, predictable gastric emptying rate, less variable absorption profiles, high bioavailability with minimum plasma fluctuations of drugs, controlled and targeted drug delivery, and reduced side effects.

The development of an effective MiNaDDS, however, invariably involves rational blending of a plethora of polymers and excipients. Optimizing the formulation composition and the manufacturing process of such a drug delivery product to furnish the desired quality traits is, therefore, a Herculean task. The traditional approach of optimizing a formulation or process essentially entails studying the influence of one variable at time (OVAT), while keeping others as constant. Using this OVAT approach, the solution of a specific problematic property can be achieved somehow, but attainment of the true optimum composition or process is never guaranteed. ${ }^{[1]}$ This may be ascribed to the presence of interactions, i.e., the influence of one or more factors on others. The final product may be satisfactory but mostly suboptimal, as a better formulation might still exist for the studied conditions. Thus, the conventional OVAT approach of drug formulation development suffers from several pitfalls, like being strenuous, uneconomical, and inept to reveal interactions. Further, the OVAT methodology results only in "just satisfactory" solutions, as a detailed study of all variables is not possible. As one 
cannot establish "cause-and-effect” relationships using OVAT, it becomes futile when all variables are changed simultaneously. Also, the technique is highly time-consuming as it leads to unnecessary runs and batches.

Several drug product inconsistencies tend to prevail generally due to inadequate knowledge of the causal factor and response relationship during the OVAT approach. Of late, the systematic optimization approaches are being widely practiced to alleviate such inconsistencies. ${ }^{[2,3]}$ This holistic approach encompassing the application of apt experimental designs coupled with the generation of mathematical equations and graphic outcomes, and depicting a complete picture of variation of the response(s) as a function of the factor(s) is termed as design of experiments (DoE). DoE techniques are thus far more beneficial, as they overcome most shortcomings inherent to the traditional OVAT approach. Prominent among all, DoE techniques yield the "best solution" in the presence of competing objectives and require fewer experiments to achieve an optimum formulation. It leads to a comprehensive understanding of the formulation system and can trace and rectify a "problem" in a remarkably easier manner. Further, the screening techniques employed as a part of DoE help in finding the "important" and "unimportant" input variables. One can simulate the product or process behavior using model equation(s) and thus save a significant amount of resources, namely, time, effort, materials, and cost. The remarkable feature of $\mathrm{DoE}$ is that it can predict the performance of formulations even without preparing them, and detect and estimate the possible interactions and synergies among variables.

Of late, DoE optimization techniques are becoming a regular practice globally, not only in the design and development of an assortment of new dosage forms, but also for modifying the existing ones. Be it a drug industry, institutional drug delivery resource, or federal compliance with USFDA, ICH, NIH, or ISO, DoE is being frequently sought after in drug discovery and development. The faster emerging area of quality by design (QbD) also requires the implementation of DoE precepts during different stages of product/process transformation.

\section{BASIC TERMINOLOGY}

The word optimize simply means to make as perfect, effective, or functional as possible. The term optimized has been used in the past to suggest that a product has been improved to accomplish the objectives of a development scientist. With respect to drug formulations or pharmaceutical processes, optimization is a phenomenon of finding "the best" possible composition or operating conditions. Accordingly, optimization has been defined as the implementation of systematic approaches to achieve the best combination of product and/or process characteristics under a given set of conditions. Of the numerous technical terms employed during DoE optimization, the vital ones are summarized in Box 1 .

\section{METHODOLOGY}

The conduct of an experiment and the subsequent interpretation of its experimental outcome are the twin essential features of the general scientific methodology. ${ }^{[4]}$ This can be accomplished only if the experiments are carried out in a systematic way and the inferences are drawn accordingly. The theme of the DoE optimization methodology provides thought-through and thorough information on diverse DoE aspects organized in a seven-step sequence as described in Figure 1.

The optimization study begins with Step I, where an endeavor is made to ascertain the initial drug delivery objective(s) in an explicit manner. Various main response parameters, which closely and pragmatically epitomize the objective(s), are chosen for the purpose. In Step II, the experimenter has several potential independent product and/or process variables to choose from. By executing a set of suitable screening techniques and designs, the formulator selects the vital few influential factors among the possible "so many" input variables. Before going to the more detailed study, experimental studies are undertaken to define the broad range of factor levels as well. During Step III, an apposite experimental design is worked out on the basis of the study objective(s), and the number and the type of factors, factor levels, and responses being explored. Working details on variegated vistas of the experimental designs, customarily required to implement the DoE optimization of drug delivery, have been elucidated in the subsequent section. Afterward, the response surface methodology (RSM) is characteristically employed to relate a response variable to the levels of input variables, and a design matrix is generated to guide the drug delivery scientist to choose optimal formulations. In Step IV, the drug delivery formulations are experimentally prepared according to the approved experimental design, and the chosen responses are evaluated. Later in Step V, a suitable mathematical model for the objective(s) under exploration is proposed, the experimental data thus obtained are analyzed accordingly, and the statistical significance of the proposed model discerned. Optimal formulation compositions are searched within the experimental domain, employing graphical or numerical techniques. This entire exercise is invariably executed with the help of pertinent computer software. Step VI is the penultimate phase of the optimization exercise, involving the validation of the response prognostic ability of the model put forward. The drug delivery performance of some studies, taken as the checkpoints, is assessed vis-à-vis that is predicted using RSM, and the results are critically compared. Finally, during Step VII, which is carried out in the industrial milieu, the process is scaled up and set forth ultimately for the production cycle.

\section{EXPERIMENTAL DESIGNS}

An experimental design constitutes the pith of the entire DoE exercise. Before the selection of an experimental design, it is essential to demarcate the experimental domain (i.e., the area to be investigated) within the factor space (i.e., the broad range 
of factor studies). To accomplish this task, first a pragmatic range of an experimental domain is embarked upon and the

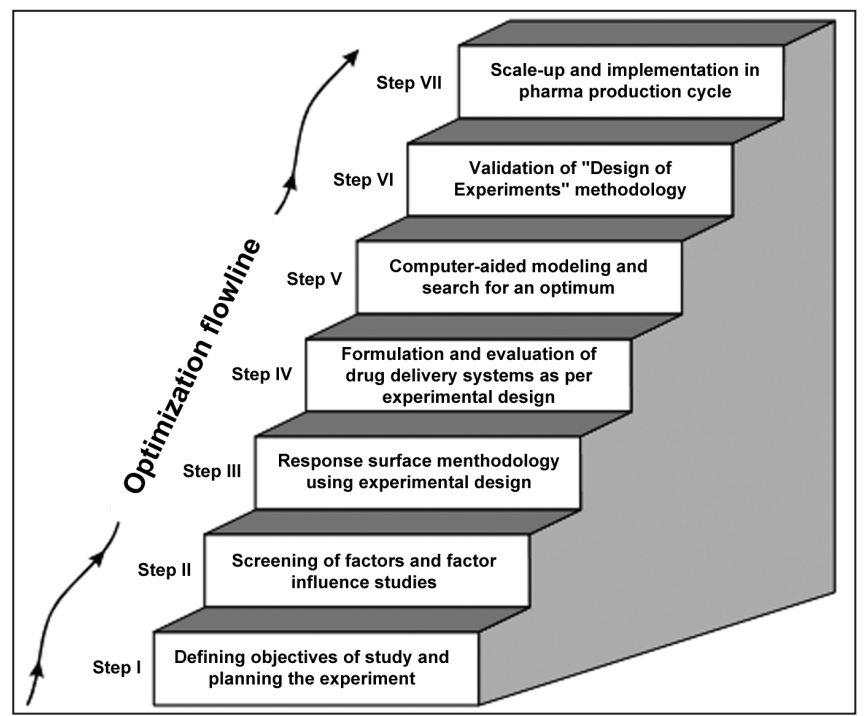

Figure 1: Seven-step ladder for optimizing drug delivery systems (figure adopted from ref. ${ }^{[1]}$ ) levels and their number are selected so that the optimum lies within its realm. While selecting the levels, one must see that the increments between them should be realistic. Too wide increments may miss finding the useful information between the levels, while a too narrow range may not yield accurate results.

There are numerous types of experimental designs to choose from. Various commonly employed experimental designs for RSM, screening, and factor influence studies during the pharmaceutical product/process development of micro/ nanoparticulate systems include
(a) Factorial designs
(b) Fractional factorial designs
(c) Plackett-Burman designs
(d) Optimal designs
(e) Central composite designs
(f) Box-Behnken designs
(g) Taguchi designs
(h) Equiradial designs
(i) Mixture designs

\section{Box 1: Key terms used in DoE optimization}

\section{Vital terms and their explanation}

- Independent variables: The input variables which are directly under the control of the product development scientist

- Factor: Experimentally controlled independent variable affecting the performance of a product or process

- $\quad$ Categorical factor: Qualitative input factor, e.g., type of polymer, tablet machine, etc.

- Signal factor: Controllable input variables influencing a response

- $\quad$ Nuisance factors: Uncontrollable factors which complicate the estimation of effects and interactions

- Robust: A product or process which is less variable to external uncontrollable influences

- Quantitative factor: Input variable with a continuous numeric value

- Levels: Values assigned to a factor

- $\quad$ Constraints: Restrictions imposed on levels of a factor

- Response: Measured system property to estimate an experimental outcome

- Effect: Magnitude of the change in response by varying factor level(s)

- Main effect: Factor effects averaged at all other factor levels

- Interaction: Lack of additivity of factor effects

- Orthogonality: Sole dependence on main factor(s) and independence from interactions

- Confounding: Aliasing, equaling, or lack of orthogonality or independence of variables

- Experimental design: A statistical strategy for organizing the experiments in such a manner that the required information is obtained as efficiently and precisely as possible

- Randomization: An unbiased way of treatment allocation to experimental units

- Replication: Number of units employed for each treatment

- Error control: Grouping of a specific type of experiments to increase experimental precision

- Runs: Experiments conducted according to the selected experimental design

- Design matrix: The layout of experimental runs in a matrix form

- Design augmentation: Enhancement, extension, and reuse of a primitive experimental design to a more advanced one

- Design resolution: The measurement of degree of confounding in an experimental design

- Response surface plot: A 3D graphical representation of a response plotted between two independent variables and one response variable

- Contour plot: Geometric illustration of a response obtained by plotting one independent variable against another, holding the magnitude of the response and other variables as constant

- Contour lines: Curves drawn on a contour plot corresponding to a response value

- $\quad$ Factor space: Dimensional space defined by the coded variables

- Experimental domain: Part of the factor space, investigated experimentally for optimization

- Response surface designs: Designs facilitating response surfaces by allowing the estimation of the main effect, interaction and even quadratic effects

- $\quad$ Screening designs: Experimental designs employed for the purpose of factor screening

- $\quad$ Empirical model: Mathematical model describing the factor-response relation using polynomials

- Rotatable design: Experimental design where the prediction ability of a response is constant in all directions at a given distance from the center point of the domain

- Residual: Quantitative difference between the observed value of a variable and the value predicted using the proposed model

- Outlier: An unusually different response value as compared to the predicted values 


\section{Table 1: Various experimental designs employed during drug delivery optimization}

\begin{tabular}{|c|c|}
\hline Design & Description \\
\hline $\begin{array}{l}\text { Factorial } \\
\text { designs (FD) }\end{array}$ & $\begin{array}{l}\text { A factorial experiment is one in which all levels } \\
(x) \text { of a given factor }(k) \text { are combined with all } \\
\text { levels of every other factor in the experiment } \\
\text { and the total number of experiments are } x^{k}\end{array}$ \\
\hline $\begin{array}{l}\text { Fractional } \\
\text { factorial } \\
\text { designs (FFD) }\end{array}$ & $\begin{array}{l}\text { In cases where there are large numbers } \\
\text { of factors, it is possible that the highest } \\
\text { order interactions have no significant effect. } \\
\text { Number of experiments can be reduced in } \\
\text { a systematic way with the resulting design } \\
\text { called as FFD. An FFD is a finite fraction }\left(1 / x^{r}\right) \\
\text { of a complete or full FD, where } r \text { is the degree } \\
\text { of fractionation and } x^{k-r} \text { is the total number of } \\
\text { experiments required }\end{array}$ \\
\hline
\end{tabular}

Diagrammatic representation
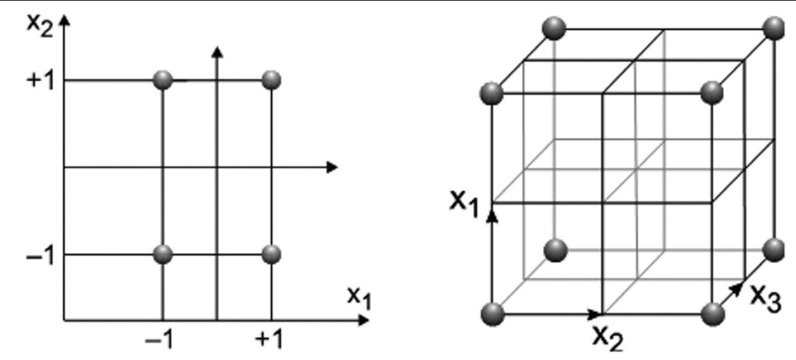

(a) $2^{2} \mathrm{FD}$; (b) $2^{3} \mathrm{FD}$
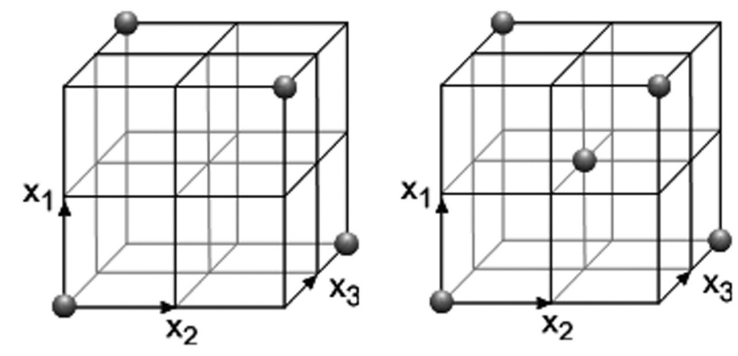

(a) $2^{3-1}$ FFD with design points as spheres; (b) $2^{3-1}$ FFD with an added center point

Plackett-

Burman

designs (PBD)

Central

composite

designs (CCD)

or Box-Wilson

design

Box-Behnken designs (BBD)

A specially made design, the $\mathrm{BBD}$, requires only three levels for each factor, i.e., -l, 0 , and +1 . A BBD is an economical alternative to $C C D$ order models, CCDs are most frequently employed. The "composite design" contains an imbedded $\left(2^{k}\right)$ FD or $\left(2^{k-r}\right)$ FFD, augmented with a group of star points $(2 \mathrm{k})$ and a "central" point. The total number of factor combinations in a CCD is given by $2^{k}+2 k+1$.
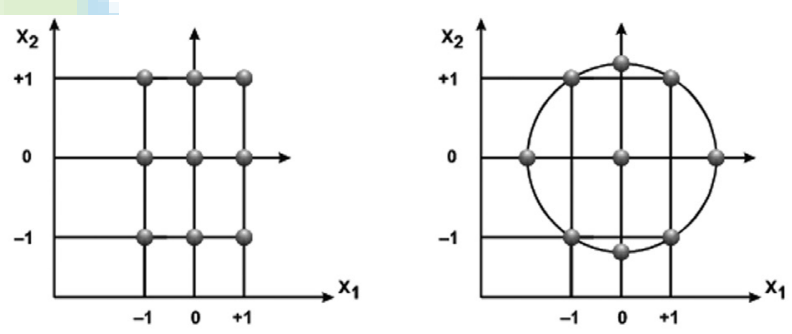

(a) CCD (rectangular domain) with $\alpha=1$; (b) CCD (spherical domain) with $\alpha=1.414$

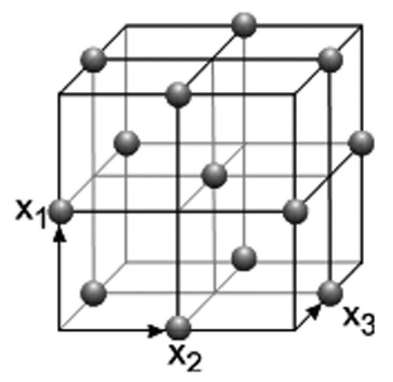

BBD for three factors
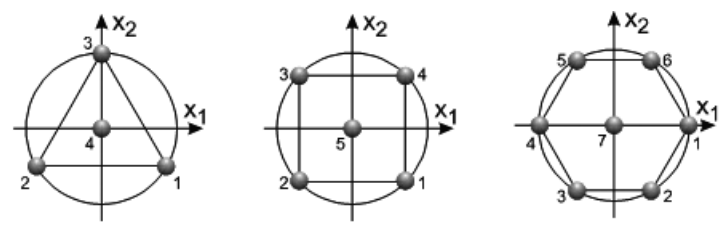

Two-factor ErD: (a) triangular four-run design; (b) square five-run design; (c) hexagonal Doehlert design 


\begin{tabular}{|c|c|c|}
\hline Design & Description & Diagrammatic representation \\
\hline $\begin{array}{l}\text { Simplex } \\
\text { mixture designs } \\
(\text { SMD) }\end{array}$ & $\begin{array}{l}\text { In DDS with multiple excipients, the } \\
\text { characteristics of the finished product usually } \\
\text { depend not so much on the quantity of each } \\
\text { substance present but on their proportions. } \\
\text { Mixture designs are highly recommended in } \\
\text { such cases }\end{array}$ & MSD: (a) linear model; (b) quadratic model \\
\hline $\begin{array}{l}\text { Taguchi } \\
\text { designs (TD) }\end{array}$ & $\begin{array}{l}\text { Offline quality control design, as it ensures } \\
\text { good performance in the development of } \\
\text { robust products or processes with "I" referring } \\
\text { to the inner array and "E" as the outer array }\end{array}$ & An inner $2^{3}$ and outer $2^{2}$ array TD \\
\hline $\begin{array}{l}\text { Optimal } \\
\text { designs }\end{array}$ & $\begin{array}{l}\text { When the domain is irregular in shape, optima } \\
\text { generated by exchange algorithm using a com }\end{array}$ & $\begin{array}{l}\text { signs can be used. These are the nonclassic custom designs } \\
\text { er }\end{array}$ \\
\hline
\end{tabular}

The salient features of above-mentioned designs are briefly stated in Table 1.

\section{Selection of the experimental design}

The choice of a design among the various types of available options depends upon the amount of resources available and the degree of control over making wrong decisions (i.e., Type I and Type II errors for testing hypotheses) that the experimenter desires. It is a good idea to choose a design that requires somewhat fewer runs than the budget permits, so that the center point runs can be added to check for curvature in a two-level screening design and backup resources are available to redo runs that have processing mishaps. By and large, low-resolution designs like FDs (full or fractional), PBDs, or Taguchi designs suffice the purpose of simpler screening of a large number of experimental parameters. Screening designs support only the linear responses. Thus, if a nonlinear response is detected, or a more accurate picture of the response surface is required, a more complex design type is necessary. Hence, when the investigator is interested in estimating interaction and even quadratic effects, or intends to have an idea of the local shape of the response surface, the response surface designs, capable of detecting curvatures, are used. The compilation in Table 2 acts as a help guide while selecting an experimental design, based upon the desired motive of the study.

\section{Search for the optimum}

Optimization of one response or the simultaneous optimization of multiple responses can be accomplished either graphically or numerically.
Graphical optimization

Known popularly as response surface analysis, graphical optimization displays the area of feasible response values in the factor space. One or more of the following techniques may be employed for this purpose.

$\mathrm{FD}=$ fractional design; FFD = fractional factorial design; $\mathrm{PBD}=$ Plackett-Burman design; $\mathrm{CCD}=$ central composite design; $\mathrm{BBD}=\mathrm{Box}-\mathrm{Benkhen}$ design; $\mathrm{SMD}=$ simplex mixture design; TGD = Taguchi design; D-OD = D-optimal design; $\mathrm{EQD}=$ equiradial design .

\section{Location of the stationary point}

After completing the experimental work, often the goal of the formulation scientist is to locate the optimum. Figure $2 \mathrm{a}$ and $\mathrm{b}$ shows the location of the stationary points in the case of a maximum and minimum, respectively. The case in which the stationary point is not a maximum or minimum is known as the saddle point, as shown in Figure 2c.

When the number of factors investigated is large, i.e., more than two, use of a graphical procedure cannot be interpreted with dexterity.

\section{Search methods}

Search brute force methods are employed for choosing the upper and lower limits of the responses of interest. The response surfaces in these search methods, as defined by the appropriate equations, are searched to find the combination of independent variables yielding the optimum. Two major steps are used - feasibility search and grid search. The feasibility search method is used to locate a set of response constraints that are just at the limit of 


\begin{tabular}{|c|c|c|c|c|c|c|c|c|c|c|}
\hline $\begin{array}{l}\text { Design } \rightarrow \\
\text { Trait } \downarrow\end{array}$ & $2^{\mathrm{k}} \mathrm{FD}$ & $x^{k} \mathrm{FD}$ & FFD & PBD & CCD & BBD & SMD & TGD & D-OD & EQD \\
\hline \multicolumn{11}{|l|}{ Factor type } \\
\hline Formulation & $\checkmark$ & $\checkmark$ & $\checkmark$ & $\checkmark$ & $\checkmark$ & $\checkmark$ & $\checkmark$ & $\checkmark$ & $\checkmark$ & $\checkmark$ \\
\hline Process & $\checkmark$ & $\checkmark$ & $\checkmark$ & $\checkmark$ & $\checkmark$ & $\checkmark$ & - & $\checkmark$ & $\checkmark$ & $\checkmark$ \\
\hline Both & $\checkmark$ & $\checkmark$ & $\checkmark$ & $\checkmark$ & $\checkmark$ & $\checkmark$ & - & $\checkmark$ & $\checkmark$ & $\checkmark$ \\
\hline \multicolumn{11}{|l|}{ Number of factors } \\
\hline$\leq 3$ & $\checkmark$ & $\checkmark$ & $\checkmark$ & $\checkmark$ & $\checkmark$ & $\checkmark$ & $\checkmark$ & $\checkmark$ & $\checkmark$ & $\checkmark$ \\
\hline $4-6$ & $\checkmark$ & $\checkmark$ & $\checkmark$ & $\checkmark$ & $\checkmark$ & $\checkmark$ & & $\checkmark$ & $\checkmark$ & $\checkmark$ \\
\hline$>6$ & & & $\checkmark$ & & & & & $\checkmark$ & & \\
\hline \multicolumn{11}{|l|}{ Factor level } \\
\hline & $\checkmark$ & - & $\checkmark$ & $\checkmark$ & - & - & $\checkmark$ & $\checkmark$ & $\checkmark$ & $\checkmark$ \\
\hline$\geq 3$ & - & $\checkmark$ & & - & $\checkmark$ & $\checkmark$ & $\checkmark$ & $\checkmark$ & $\checkmark$ & \\
\hline \multicolumn{11}{|l|}{ Model proposed } \\
\hline Linear model & $\checkmark$ & $\checkmark$ & $\checkmark$ & $\checkmark$ & $\checkmark$ & $\checkmark$ & - & $\checkmark$ & $\checkmark$ & $\checkmark$ \\
\hline Interaction model & $\checkmark$ & $\checkmark$ & $\checkmark$ & $\checkmark$ & $\checkmark$ & $\checkmark$ & $\checkmark$ & $\checkmark$ & & $\checkmark$ \\
\hline Quadratic model & - & $\checkmark$ & - & - & - & - & - & - & & - \\
\hline Mixture model & - & - & - & - & - & - & $\checkmark$ & - & & - \\
\hline $\begin{array}{l}\text { Custom-made } \\
\text { model }\end{array}$ & - & - & & - & & & - & & & \\
\hline $\begin{array}{l}\text { Screening and factor } \\
\text { influence study }\end{array}$ & $\checkmark$ & $\checkmark$ & $\checkmark$ & $\checkmark$ & - & - & $\checkmark$ & $\checkmark$ & $\checkmark$ & - \\
\hline $\begin{array}{l}\text { Response surface } \\
\text { mapping }\end{array}$ & & $\checkmark$ & $\checkmark$ & & $\checkmark$ & $\checkmark$ & $\checkmark$ & $\checkmark$ & $\checkmark$ & $\checkmark$ \\
\hline
\end{tabular}

possibility. Subsequently, the exhaustive grid search is applied, wherein the experimental range is further divided into a grid of specific size and searched methodically.

\section{Overlay plots}

The response surfaces or contour plots are superimposed over each other to search for the best compromise visually, as depicted in Figure 3. Minimum and maximum boundaries are set for acceptable objective values. The region is highlighted wherein all the responses are acceptable. Within this area, an optimum is located, trading off different responses. An overlay plot can also be termed as a combined contour plot.

\section{Mathematical optimization methods (numerical optimization)}

Graphical analysis is usually preferred in the case of a single response. However, in cases of multiple responses, it is usually advisable to conduct numerical or mathematical optimization first to uncover a feasible region.

Desirability function involves a way of overcoming the difficulty of multiple, sometimes opposing, responses. Objective function methods are used to seek an optimum formulation by solving for a maximum or a minimum in the presence of equality and/or inequality constraints. The Lagrangian method can be used for the optimization of functions expressed by introducing a slack variable for each inequality constraint.

\section{Model diagnostic plots}

The goodness of fit of a model can be investigated using one or more of the plots illustrated in Figure 4:

- Actual versus predicted: A graph is plotted between the actual

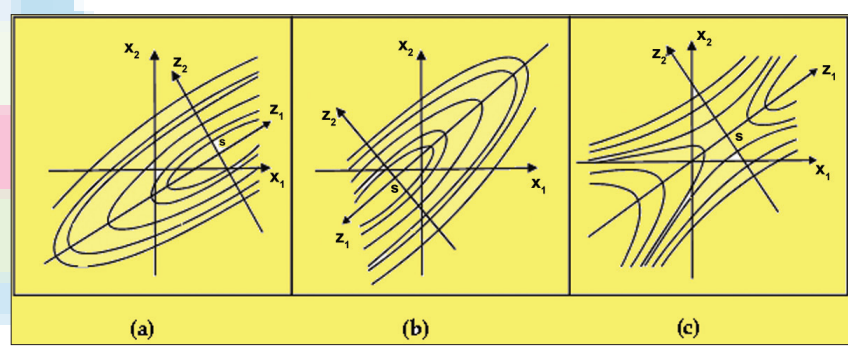

Figure 2: Diagrammatic representation of contour lines for the location of the stationary point, S. (a) Maximum; (b) minimum; (c) saddle point

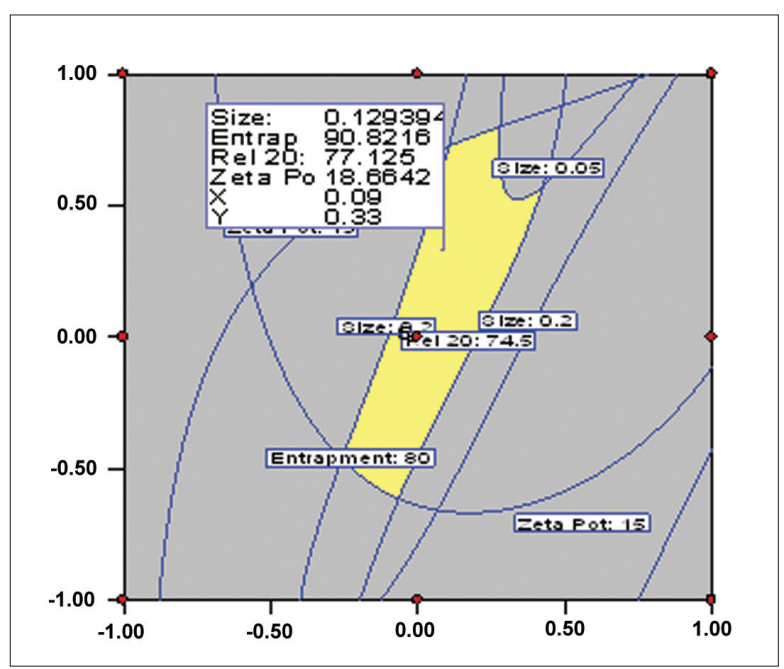

Figure 3: A contour overlay plot

and the predicted response values. ${ }^{[5-7]}$ This helps in detecting a value or a group of values that are not easily predicted by the model. 


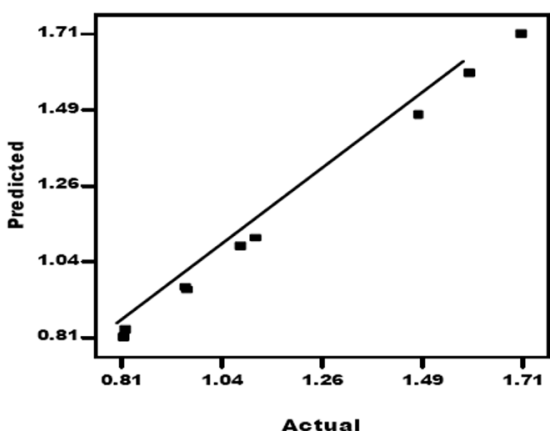

(a)

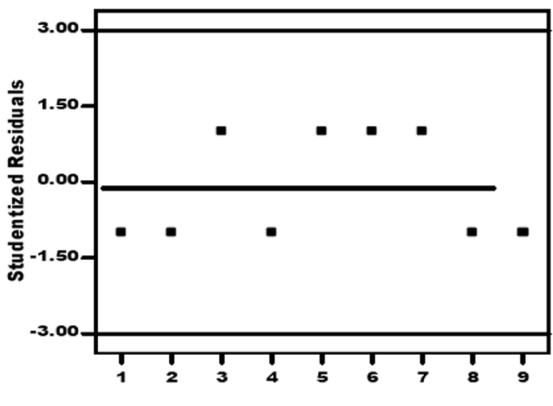

Run Number

(c)

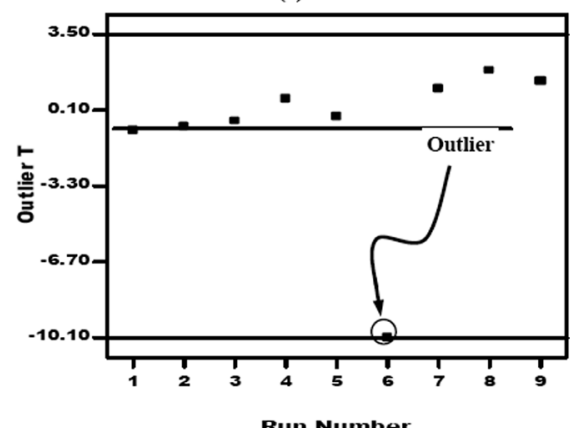

(e)

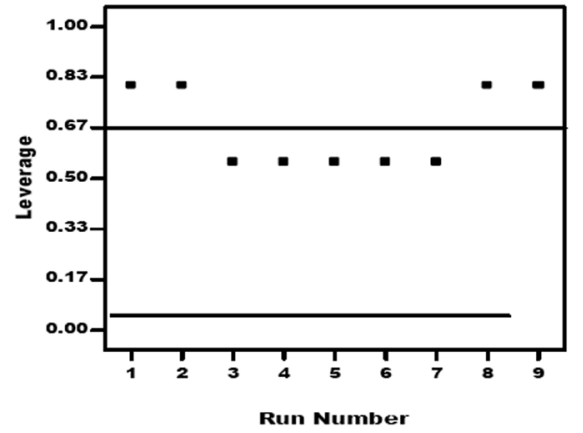

(g)

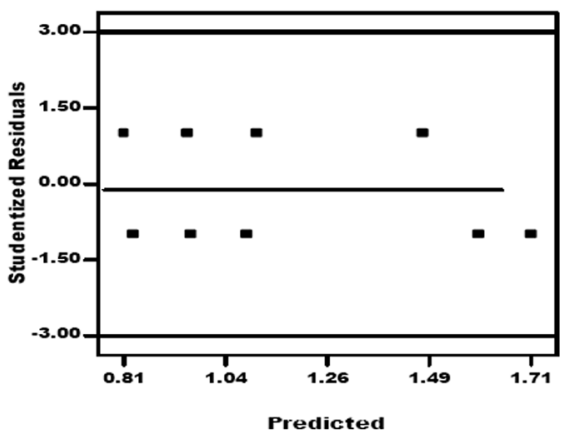

(b)

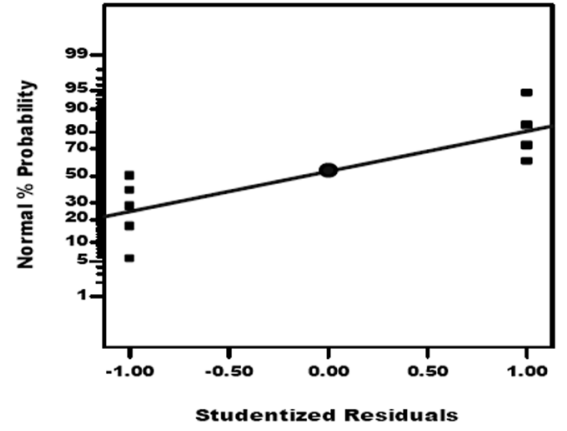

(d)

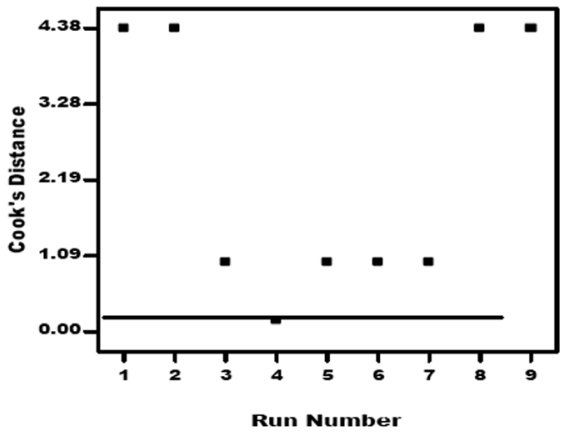

(f)

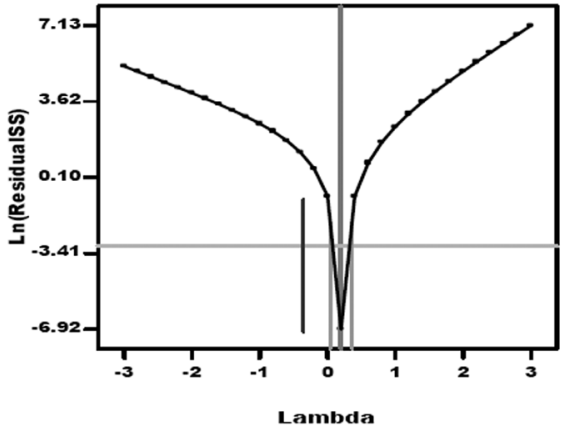

(h)

Figure 4: Model diagnostic plots to investigate the goodness of the fit of the proposed model(s). (a) Predicted versus actual; (b) studentized residuals versus predicted; (c) studentized residuals versus run; (d) normal probability plots; (e) outlier T plot; (f) Cook's distance plot; (g) leverage plot; (h) Box-Cox plot (figure adopted from ref. ${ }^{[1]}$ )

- Residuals versus predicted: Residual (or error) is the quantitative difference between the observed and the predicted response(s). Studentized residuals are the residuals converted to their standard deviation units.

- Residuals versus run: This is a plot of the residuals versus the order of the experimental runs. It checks for the "lurking variables" that may have influenced the response during the experiment.

- Residuals versus factor: This is a plot of the residuals versus any selected factor. It checks whether the variance, not accounted for by the model, is different for different levels of a factor. 
- Normal probability plot: It investigates the normal probability distribution of residuals, as judged from the linear trend of the points, when plotted on a probit scale.

- Outlier T: This is a measure of by how many standard deviations the actual value deviates from the value predicted after deleting the point in question.

- Cook's distance: This provides measures of the influence, potential or actual, of the individual runs. ${ }^{[8]}$

- Leverage: This is a measure of the degree of influence of each point on the model fit.

- Box-Cox plot for power transforms: The Box-Cox plot is a tool to help determine the most appropriate power transformation for the application to response data. ${ }^{[9]}$

\section{Computer use in optimization}

The merits of DoE optimization techniques are galore and their acceptability upbeat. Putting such rational approaches into practice, however, usually involves a great deal of mathematical and statistical intricacies. Today, with the availability of powerful and economical hardware and that of the comprehensive DoE software, the erstwhile computational hiccups have been greatly simplified and streamlined. Computer software have been used almost at every step during the entire optimization cycle ranging from the selection of design, screening of factors, use of response surface designs, generation of the design matrix, plotting of 3D response surfaces and $2 \mathrm{D}$ contour plots, application of optimum search methods, interpretation of the results, to finally, the validation of the methodology. Hence, when selecting a DoE software package, it is important to look for not only a statistical engine that is fast and accurate, but also the following:

- A simple graphic user interface (GUI) that is intuitive and easy-to-use

- A well-written working manual with tutorials to get off to a quick start

- A wide selection of designs for screening and optimizing processes or product formulations

- A spreadsheet flexible enough for data entry as well as dealing with missing data and changed factor levels

- Graphic tools displaying the rotatable 3D response surfaces, 2D contour plots, interaction plots, and the plots revealing model diagnostics

- Facility to randomize the order of experimental runs

- Design evaluation tools that will reveal aliases (i.e., confounded or equal effects) and other potential pitfalls

- After-sales technical support, online help, and training offered by manufacturing vendors.

Box 2 lists some commonly used computer software packages for DoE optimization, especially in pharmacircles, along with their respective web sources.

\section{Drug delivery optimization: A literature instance}

DoE has successfully been employed to optimize wide-ranging objectives in pharmaceutical sciences including preformulation studies, stability kinetic studies, organoleptic evaluation of a drug

\begin{tabular}{|c|c|}
\hline $\begin{array}{l}\text { Design Expert } \\
\text { www.statease.com }\end{array}$ & $\begin{array}{l}\text { JMP } \\
\text { www.jmp.com }\end{array}$ \\
\hline $\begin{array}{l}\text { DOE PRO XL and DOE KISS } \\
\text { www.sigmazone.com }\end{array}$ & $\begin{array}{l}\text { ECHIP } \\
\text { www.echip.com }\end{array}$ \\
\hline $\begin{array}{l}\text { STATISTICA } \\
\text { www.statoftinc.com }\end{array}$ & $\begin{array}{l}\text { OPTIMA } \\
\text { www.optimasostware.co.uk }\end{array}$ \\
\hline $\begin{array}{l}\text { Omega } \\
\text { www.winomega.com }\end{array}$ & $\begin{array}{l}\text { iSIGHT } \\
\text { www.engenious.com }\end{array}$ \\
\hline $\begin{array}{l}\text { SOLVER } \\
\text { www.solver.com }\end{array}$ & $\begin{array}{l}\text { GRG2 } \\
\text { www.fp.mcs.anl.gov }\end{array}$ \\
\hline $\begin{array}{l}\text { MINITAB } \\
\text { www.minitab.com }\end{array}$ & $\begin{array}{l}\text { SPSS } \\
\text { www.spss.com }\end{array}$ \\
\hline $\begin{array}{l}\text { MATREX } \\
\text { www.rsd-associates.com/ } \\
\text { matrex.htm }\end{array}$ & $\begin{array}{l}\text { COMPACT } \\
\text { www.fp.mcs.anl.gov }\end{array}$ \\
\hline
\end{tabular}

or its formulation, drug-excipient interactions, performance evaluation procedures of the formulation or process, procedures, procedures for assaying the drug content, or validation of the methods. ${ }^{[10]}$

Also, experimental designs have long been employed to optimize various industrial products and/or processes like, FDs since 1926, the screening designs since $1946,{ }^{[11]}$ CCDs since $1951,{ }^{[12]}$ and SMDs since 1958. ${ }^{[13]}$ The use of optimization techniques using DoE, however, permeated into the field of pharmaceutical product/process development around four decades ago. ${ }^{[10]}$

The first literature report on the rational use of optimization appeared in 1967, when a tablet of sodium salicylate was optimized using an FD. ${ }^{[14]}$ Since then, these systematic approaches have been put into practice in the development of drug formulations at a steady pace. Among the conventional dosage forms, tablets have predominantly been investigated for the purpose, whereas, among various DDS, CR matrices have majorly been studied, followed by microparticulates and nanoparticulates. An updated account of DoE optimization studies on MiNaDDS is provided herein.

\section{Microparticulate systems}

Microparticulate systems offer numerous advantages not only to pharmaceutical sciences but all biomedical sciences. Microencapsulation helps to separate a core material from its environment until it is released, thereby improving its stability, extending the core's shelf-life, and providing a sustained and controlled release. Owing to these salient advantages, the literature abounds in reports regarding the formulation of microparticles, microcapsules, and microspheres. Table 3 provides a selected instance of various microparticulate systems optimized using DoE.

\section{Nanoparticulate/nanostructured systems}

Pharmaceutical nanotechnology has witnessed a recent upsurge due to several advantages of nanoparticles over other drug delivery systems. Their size allows them to be administered 


\begin{tabular}{|c|c|c|c|}
\hline \multicolumn{4}{|l|}{ Microspheres } \\
\hline Drug & Factors/polymers & Design & Year \\
\hline Aspirin & Amount of calcium alginate & ANN & $2010^{[15]}$ \\
\hline Prednisolone acetate & Molecular weight of polymer, polymer conc., theoretical drug loading & FD & $2010^{[16]}$ \\
\hline Riboflavin sodium phosphate & Amount of calcium alginate & RSM & $2009^{[17]}$ \\
\hline Rosiglitazone maleate & Polymer-to-drug ratio, conc. of the polymer, stirring speed & FD & $2009^{[15]}$ \\
\hline Seratiopeptidase & Polymer conc., external aqueous phase volume & FD & $2009^{[18]}$ \\
\hline Lacidipine & Polymer conc., volume of glutaraldehyde, stirring speed, cross-linking time & CCD & $2009^{[19]}$ \\
\hline Verapamil $\mathrm{HCl}$ & External phase $\mathrm{pH}$, polymer conc., initial drug load & ANN & $2009^{[20]}$ \\
\hline Insulin & Conc. of cross-linking agent, stirring speed, polymer concentration & BBD & $2009^{[21]}$ \\
\hline Theophylline & Temperature, drug loading, amount of solvent & BBD & $2008^{[22]}$ \\
\hline Heparin & Polymer conc., inlet temperature, liquid feed low rate & FD & $2008^{[23]}$ \\
\hline Amoxicillin & Drug-to-polymer ratio, stirring speed & FD & $2008^{[24]}$ \\
\hline Flurbiprofen & $\begin{array}{l}\% \text { w/v polyvinyl alcohol, aqueous phase conc., PHBV conc. in aqueous } \\
\text { phase }\end{array}$ & CCD & $2008^{[25]}$ \\
\hline 5-fluorouracil & $\begin{array}{l}\text { Polymer conc., ratio of the drug to the polymer, amount of the cross-linking } \\
\text { agent, stirring speed }\end{array}$ & OD & $2008^{[26]}$ \\
\hline Amoxicillin & Polymer-to-drug ratio and stirring speed & FD & $2007^{[24]}$ \\
\hline Fluorescein isothiocynate & Poly(epsilon-caprolactone) & FD & $2006^{[27]}$ \\
\hline Glipizide & Polymer-to-drug ratio and stirring speed & FD & $2005^{[28]}$ \\
\hline Cyclosporine & Polymer and surfactant amounts, and organic solvent volume, stirring speed & CCD & $2002^{[29]}$ \\
\hline \multicolumn{4}{|l|}{ Microparticles } \\
\hline Benznidazole & Encapsulation efficiency, size, yield, and dissolution rate & ANN & $2009^{[30]}$ \\
\hline Etoposide & Ratio of drug and polymer, and drug and surfactant & FD & $2010^{[31]}$ \\
\hline Paclitaxel & $\begin{array}{l}\text { Conc. of Brij, amount of TPGS ( } \alpha \text {-tocopheryl polyethylene glycol-1000 } \\
\text { succinate }\end{array}$ & Taguchi & $2009^{[32]}$ \\
\hline Alpha tocopherol & Ratio of pectin to alpha-tocopherol, emulsifier concentration, $\mathrm{CaCl}_{2}$ conc. & CCD & $2009^{[33]}$ \\
\hline Glutathione & $\begin{array}{l}\text { Volume of liquid paraffin, the HP-beta-CD amount, and the drug/polymer } \\
\text { ratio }\end{array}$ & $\begin{array}{l}\text { Multilevel } \\
\text { experimental } \\
\text { design }\end{array}$ & $2007^{[34]}$ \\
\hline Bovine serum albumin (BSA) & $\begin{array}{l}\text { Polyvinyl pyrrolidone (PVP) conc., BSA/PCL ratio, w/o/o/o ratio, and PEG/ } \\
\text { PCL ratio }\end{array}$ & FD & $2001^{[35]}$ \\
\hline
\end{tabular}

\begin{tabular}{|c|c|c|c|}
\hline \multicolumn{4}{|l|}{ Polymeric nanoparticles } \\
\hline Drug & Factors/polymers & Design & Year \\
\hline Paclitaxel & Amount of polymer, duration of ultrasonication & RCCD & $2010^{[36]}$ \\
\hline Gentamycin & Molecular weight of PLLA & Orthogonal design & $2009^{[37]}$ \\
\hline Tanshinone & - & CCD & $2007^{[38]}$ \\
\hline Thymopentin & - & CCD & $2006^{[39]}$ \\
\hline Amphiphilic beta-cyclodextrin & Water fraction, acetone fraction, and ethanol fraction & Mixture design & $2005^{[40]}$ \\
\hline Insulin & $\begin{array}{l}\text { Ratio of polymers (PCL/RS ratio), volume, and } \mathrm{pH} \text { of the } \\
\text { aqueous solution of polyvinyl alcohol }\end{array}$ & CCD & $2005^{[41]}$ \\
\hline 5-fluorouracil & $\begin{array}{l}\text { Type of surfactant, amount of acetone, and molecular } \\
\text { weight of the polymer }\end{array}$ & Orthogonal design & $2005^{[42]}$ \\
\hline \multicolumn{4}{|l|}{ Solid lipid nanoparticles } \\
\hline Quercetin & Amount of Compritol and Tween 80 & CCD & $2010^{[43]}$ \\
\hline Vitamin $\mathrm{K} 1$ & Concentrations of the surfactants, Myverol, and Pluronic & $\begin{array}{l}\text { CCD } \\
\text { RSM }\end{array}$ & $2010^{[44]}$ \\
\hline Amikacin & $\begin{array}{l}\text { Particle size, drug loading, and zeta potential, amount of lipid } \\
\text { phase, ratio of the drug to lipid, and volume of aqueous phase }\end{array}$ & CCD & $2010^{[45]}$ \\
\hline Simvastatin & $\begin{array}{l}\text { Amount of glycerol monostearate, concentration of } \\
\text { poloxamer, and volume of isopropyl alcohol }\end{array}$ & FD & $2010^{[46]}$ \\
\hline Buspirone-HCl & $\begin{array}{l}\text { Surfactant percentage, speed of the homogenizer, acetone- } \\
\text { to-DCM ratio, lipid type }\end{array}$ & BBD & $2009^{[47]}$ \\
\hline Allopurinol & Drug-to-wax ratio & FD & $2005^{[48]}$ \\
\hline
\end{tabular}


intravenously via injection unlike other colloidal systems which occlude both needles and capillaries. Due to their small size, they can pass through the sinusoidal spaces in the bone marrow and spleen more efficiently as compared to other systems like microspheres. Also, due to their large surface area, they have a higher loading capacity. Table 4 provides a selected instance of various polymeric and lipidic nanoparticulate systems optimized using DoE.

\section{Self-emulsifying systems}

Self-emulsifying drug delivery systems (SEDDS) possess unparalleled potential in improving the oral bioavailability of poorly water-soluble drugs. Following their oral administration, these systems rapidly disperse in gastrointestinal fluids, yielding micro- or nanoemulsions containing the solubilized drug. Owing to its miniscule globule size, the micro/nanoemulsified drug can easily be absorbed through lymphatic pathways, bypassing the hepatic first-pass effect. Table 5 provides an account of selfemulsifying systems optimized using DoE.

\section{Liposomes}

Liposomes are artificially prepared vesicles made of a lipid bilayer. Liposomes can be filled with drugs, and used to deliver drugs for cancer and other diseases. Liposomes can be prepared by disrupting biological membranes, for example by sonication. Liposomes can be composed of naturally derived phospholipids with mixed lipid chains (such as egg phosphatidylethanolamine) or other surfactants. Table 6 provides an account of liposomal systems optimized using DoE.

\section{Microemulsions}

Microemulsions are clear, stable, isotropic liquid mixtures of oil, water, and surfactant, frequently in combination with a co-surfactant. The aqueous phase may contain salt(s) and/ or other ingredients, and the "oil" may actually be a complex mixture of different hydrocarbons and olefins. In contrast to ordinary emulsions, microemulsions form upon simple mixing of the components and do not require the high-shear conditions

\begin{tabular}{|c|c|c|c|}
\hline Drug & Factors/polymers & Design & Year \\
\hline Patchoulic alcohol & $\begin{array}{l}\text { Ratio of Cremophor EL, Tween 80, PEG 400, isopropyl myristate, } \\
\text { patchoulic alcohol }\end{array}$ & CCD & $2010^{[49]}$ \\
\hline Carvedilol & Amount of SPH and $0.1 \mathrm{~N} \mathrm{HCl}$ used during drug loading & FD & $2010^{[50]}$ \\
\hline Lacidipine & Amount of oil phase, surfactant, and co-surfactant & D-OD & $2010^{[51]}$ \\
\hline GBE50 & Amount of IPM and Cremophore & Orthogonal design & $2009^{[52]}$ \\
\hline Genistein & Amount of maisine, labrafac, Cremophore, labrasol, and transcutol & BBD & $2009^{[53]}$ \\
\hline Curcumin & Conc. of surfactant, co-surfactant, and oil & SLD & $2009^{[54]}$ \\
\hline Oridonin & Oil percentage, and surfactant-to-co-surfactant ratio & CCD & $2009^{[55]}$ \\
\hline Probucol & Amount of surfactant and co-surfactant & BBD & $2008^{[56]}$ \\
\hline $\begin{array}{l}\text { Antischistosomal drug } \\
\text {-QHN17 }\end{array}$ & Oil content, weight ratio of surfactant and co-surfactant & CCD & $2007^{[57]}$ \\
\hline Simvastatin & - & Mixture design & $2007^{[58]}$ \\
\hline Cyclosporine & $\begin{array}{l}\text { Amounts of Emulphor El-620, Capmul MCM-C8, and } 20 \%(w / w) \\
\text { CyA in sweet orange oil }\end{array}$ & BBD & $2007^{[59]}$ \\
\hline Ketoprofen & Conc. of the co-surfactant and gelling agent & FD & $2004^{[60]}$ \\
\hline Celecoxib & - & MD & $2004^{[61]}$ \\
\hline Coenzyme Q10 (CoQ) & Amount of $\mathrm{R}-(+)$-limonene, surfactant, and co-surfactant & BBD & $2004^{[62]}$ \\
\hline
\end{tabular}

\begin{tabular}{|c|c|c|c|}
\hline Drug & Factors/polymers & Design & Year \\
\hline Sinomenine & Proportion of phospholipid and cholesterol & Mixture design & $2009^{[63]}$ \\
\hline Ciprofloxacin & Molar concentration of ciprofloxacin and cholesterol & FD & $2009^{[64]}$ \\
\hline Benzocaine & $\begin{array}{l}\text { Surfactant concentration, volume of hydration phase, vesicle lipid phase, percentage } \\
\text { of ethanol }\end{array}$ & D-OD & $2008^{[65]}$ \\
\hline $\begin{array}{l}\text { Lidocaine } \\
\text { hydrochloride }\end{array}$ & $\begin{array}{l}\text { Conc. of the } \mathrm{CH} \text { coating solution, the dripping rate of this solution on the liposome } \\
\text { colloidal dispersion, stirring rate and the amount of the drug entrapped }\end{array}$ & FFD & $2007^{[66]}$ \\
\hline Glipizide & Amount of paraffin wax, proportion of stearic acid in the wax & FD & $2007^{[67]}$ \\
\hline $\begin{array}{l}\text { Piroxicam } \\
\text { proniosome }\end{array}$ & Molar ratio of Span 60 to cholesterol, surfactant loading, and the amount of the drug & BBD & $2007^{[68]}$ \\
\hline Leuprolide & Volume of the aqueous phase, HSPC/DSPG (negative charge) and HSPC/cholesterol & $\begin{array}{l}\text { ANN } \\
\text { FD }\end{array}$ & $2005^{[69]}$ \\
\hline $\begin{array}{l}\text { Protamine-DNA } \\
\text { complex }\end{array}$ & $\begin{array}{l}\text { Weight ratio of protamine/DNA, the weight ratio of Chems/DNA, and the molar ratio of } \\
\text { Chems/DOPE in the anionic liposomes }\end{array}$ & CCD & $2004^{[70]}$ \\
\hline Gadolinium & $\begin{array}{l}\text { Phospholipid type and amount of cholesterol), liposome size, drug/lipid ratio (loading), } \\
\text { and nature of the amphiphilic gadolinium (Gd) chelate }\end{array}$ & FFD & $2002^{[71]}$ \\
\hline
\end{tabular}




\begin{tabular}{|c|c|c|c|}
\hline Drug & Factors/polymers & Design & Year \\
\hline Bay oil & $\begin{array}{l}\text { Conc. of digalactosyl } \\
\text { diglyceride }\end{array}$ & CCD & $2009^{[72]}$ \\
\hline Quercetin & $\begin{array}{l}\text { Conc. of oil, surfactant, } \\
\text { and co-surfactant }\end{array}$ & SLD & $2009^{[73]}$ \\
\hline Flurbiprofen & $\begin{array}{l}\text { Type and conc. of } \\
\text { excipients }\end{array}$ & FD & $2008^{[74]}$ \\
\hline
\end{tabular}

generally used in the formation of ordinary emulsions. The two basic types of microemulsions are direct (oil dispersed in water, $\mathrm{o} / \mathrm{w}$ ) and reversed (water dispersed in oil, w/o).

In ternary systems such as microemulsions, where two immiscible phases (water and oil) are present with a surfactant, the surfactant molecules may form a monolayer at the interface between the oil and water, with the hydrophobic tails of the surfactant molecules dissolved in the oil phase and the hydrophilic head groups in the aqueous phase. As in the binary systems (water/surfactant or oil/surfactant), self-assembled structures of different types can be formed, ranging, for example, from (inverted) spherical and cylindrical micelles to lamellar phases and bicontinuous microemulsions, which may coexist with predominantly oil or aqueous phases. Table 7 provides an account of microemulsions optimized using DoE.

\section{EPILOG}

The pioneering approach of DoE has become an integral and cardinal phenomenon globally in drug delivery, especially in the industrial milieu. DoE optimization can make modifying the existing formulations and meeting the redefined objectives much simpler. The industrial payoffs of the approach are exceptional, as it offers product development solutions with fairly small involvement of men, materials, machination, and money. A pharmaceutical scientist should earnestly consider the use of DoE studies particularly when finding the correct compromise is not simple and straightforward. Accordingly, it has been found to be particularly valid for nanostructured and microparticulate systems.

The more the formulator knows about the system, the better he or she can define it, and the higher precision he can monitor it with. Hence, one must envision the entire DoE exercise as a whole. The hiccups in optimizing a pharmaceutical formulation are due to the difficulties in understanding the real cause-and-effect relationships. Defining the relationship between the formulation or process variables and quality traits of the formulation is almost an impossible task without the application of experimental designs. Trial and error OVAT methods, in this regard, can never allow the formulator to know the proximity of any particular formulation to optimal drug delivery solution.

Notwithstanding the outstanding benefits of DoE optimization, the experimenter should certainly not consider it as a magic wand to solve all product development problems, as there is no surrogate to the pharmaceutical wisdom, art, or rationale. A wise scientist can even choose the influential variables through his vast experience and observation, bypassing the rigors of screening and factor influence studies. If incorrect choice of experimental designs during DoE optimization can jeopardize the reliability of prediction, an inept choice of experimental domain may either miss the optimum or require much more number of experiments to find the same.

The merits of DoE are numerous and benefits galore. Still there are several experimenters in the developing nations who have not yet endeavored in DoE. A significant jump in DoE information and its impact on production capability have not yet been obtained. It is the most opportune time for them to get started first. A journey of hundred miles starts with a single leap. Eventually, the day would not be quite far when the enormous utilities of DoE could be harvested by drug industry and research to their fullest advantage.

\section{REFERENCES}

1. Singh B, Kumar R, Ahuja N. Optimizing drug delivery systems using "Design of Experiments" Part 1: Fundamental aspects. Crit Rev Ther Drug Carrier Syst 2005;22:27-106.

2. Singh B, Chakkal SK, Ahuja N. Formulation and optimization of controlled release mucoadhesive tablets of atenolol using response surface methodology. AAPS PharmSciTech 2006;7: E3.

3. Singh B, Pahuja S, Kapil R, Ahuja N. Formulation development of oral controlled release tablets of hydralazine: Optimization of drug release and bioadhesive characteristics. Acta Pharm 2009;59:1-13.

4. Singh B, Ahuja N. Response surface optimization of drug delivery systems. In: Jain NK, editor. Progress in Controlled and Novel Drug Delivery Systems. $1^{\text {st }}$ ed. New Delhi: CBS Publishers; 2004. p 470-509.

5. Singh B, Mehta G, Kumar R, Bhatia A, Ahuja N, Katare OP. Design, development and optimization of nimesulide-loaded loiposomal systems for topical application. Curr Drug Del 2005;2:143-53.

6. Singh B, Ahuja N. Development of controlled-release buccoadhesive hydrophilic matrices of diltiazem hydrochloride: Optimization of bioadhesion, dissolution, and diffusion parameters. Drug Dev Ind Pharm 2002;28:431-42.

7. Montgomery DC. Design and Analysis of Experiments. $5^{\text {th }}$ ed. New York: Wiley; 2001.

8. Cook DR. Detection of infiuential observations in linear regression. Technometrics 1977;19:15-8.

9. Box GE, Cox DR. An analysis of transformations. J Royal Stat Soc Ser B 1964;26:211-43.

10. Singh B, Dahiya M, Saharan V, Ahuja N. Optimizing drug delivery systems using "Design of Experiments" Part II: Retrospect and Prospects. Crit Rev Ther Drug Carrier Syst 2005;22:215-92.

11. Plackett RL, Burman JP. The design of optimum multifactorial experiments. Biometrica 1946;33:305-25.

12. Box GE, Wilson KB. On the experimental attainment of optimum conditions. J Royal Stat Soc Ser B 1951;13:1-45.

13. Scheffe H. Experiments with mixtures. J Royal Stat Soc Ser B 
1958;20:344-60.

14. Marlowe E, Shangraw RF. Dissolution of sodium salicylate from tablet matrices prepared by wet granulation and direct compression. J Pharm Sci 1967;56:498-504.

15. Mohan Kamila M, Mondal N, Kanta Ghosh L, Kumar Gupta B. Multiunit floating drug delivery system of rosiglitazone maleate: development, characterization, statistical optimization of drug release and in vivo evaluation. AAPS PharmSciTech 2009;10:887-99.

16. Sarisozen C, Arica B, Orman MN, Hincal AA, Calis S. Optimization of prednisolone acetate-loaded chitosan microspheres using a 2(3) factorial design for preventing restenosis. Drug 2010;17:178-86.

17. Zhang AY, Fan TY. [Optimization of riboflavin sodium phosphate loading to calcium alginate floating microspheres by response surface methodology]. Beijing Da Xue Xue Bao 2009;41:682-6.

18. Saraf $\mathrm{S}$. Process optimization for the production of nanoparticles for drug delivery applications. Expert Opin Drug Deliv 2009;6:187-96.

19. Sultana S, Bhavna, lqbal Z, Panda BP, Talegaonkar S, Bhatnagar A, Ahmad FJ. Lacidipine encapsulated gastroretentive microspheres prepared by chemical denaturation for Pylorospasm. J Microencapsul 2009;26:385-93.

20. Labouta HI, el-Khordagui LK, Molokhia AM, Ghaly GM. Multivariate modeling of encapsulation and release of an ionizable drug from polymer microspheres. J Pharm Sci 2009;98:4603-15.

21. Ubaidulla U, Khar RK, Ahmad FJ, Tripathi P. Optimization of chitosan succinate and chitosan phthalate microspheres for oral delivery of insulin using response surface methodology. Pharm Dev Technol 2009;14:96-105.

22. Miyazaki Y, Yakou S, Yanagawa F, Takayama K. Evaluation and optimization of preparative variables for controlled-release floatable microspheres prepared by poor solvent addition method. Drug Dev Ind Pharm 2008;34:1238-45.

23. Shur J, Nevell TG, Shute JK, Smith JR. The spray drying of unfractionated heparin: optimization of the operating parameters. Drug Dev Ind Pharm 2008;34:559-68.

24. Patel JK, Patel MM. Stomach specific anti-helicobacter pylori therapy: Preparation and evaluation of amoxicillin-loaded chitosan mucoadhesive microspheres. Curr Drug Deliv 2007;4:41-50

25. Coimbra PA, De Sousa HC, Gil MH. Preparation and characterization of flurbiprofen-loaded poly(3-hydroxybutyrateco-3-hydroxyvalerate) microspheres. J Microencapsul 2008; 25:170-8.

26. Zhao XL, Li KX, Zhao XF, Pang DH, Chen DW. Study on colonspecific 5-Fu pH-enzyme Di-dependent chitosan microspheres. Chem Pharm Bull (Tokyo) 2008;56:963-8.

27. Bhavsar MD, Tiwari SB, Amiji MM. Formulation optimization for the nanoparticles-in-microsphere hybrid oral delivery system using factorial design. J Control Release 2006;110:422-30.

28. Patel JK, Patel RP, Amin AF, Patel MM. Formulation and evaluation of mucoadhesive glipizide microspheres. AAPS PharmSciTech 2005;6: E49-55

29. Aberturas MR, Molpeceres J, Guzman M, Garcia F. Development of a new cyclosporine formulation based on poly(caprolactone) microspheres. J Microencapsul 2002;19:61-72.

30. Leonardi D, Salomon CJ, Lamas MC, Olivieri AC. Development of novel formulations for Chagas' disease: Optimization of benznidazole chitosan microparticles based on artificial neural networks. Int J Pharm 2009;367:140-7.

31. Yadav KS, Sawant KK. Formulation optimization of etoposide loaded PLGA nanoparticles by double factorial design and their evaluation. Current 2010;7:51-64.

32. Dong X, Mattingly CA, Tseng M, Cho M, Adams VR, Mumper RJ. Development of new lipid-based paclitaxel nanoparticles using sequential simplex optimization. Eur J Pharm Biopharm 2009;72:9-17

33. Welker TL, Congleton JL. Effect of dietary alphatocopherol + ascorbic acid, selenium, and iron on oxidative stress in sub-yearling Chinook salmon (Oncorhynchus tshawytscha Walbaum). J Anim Physiol Anim Nutr (Berl) 2009;93:15-25.

34. Trapani $A$, Laquintana $V$, Denora $N$, Lopedota $A$, Cutrignelli $A$, Franco M, Trapani G, Liso G. Eudragit RS 100 microparticles containing 2-hydroxypropyl-beta-cyclodextrin and glutathione: Physicochemical characterization, drug release and transport studies. Eur J Pharm Sci 2007;30:64-74.

35. Lin WJ, Huang LI, Chang RR. Characterization of protein-loaded poly(epsilon-caprolactone) microparticles based on a factorial design. J Microencapsul 2001;18:183-9.

36. Kollipara S, Bende G, Movva S, Saha R. Application of rotatable central composite design in the preparation and optimization of poly(lactic-co-glycolic acid) nanoparticles for controlled delivery of paclitaxel. Drug Dev Ind Pharm 2010;36:1377-87.

37. He Z, Xing J, Kong $\mathrm{H}, \mathrm{Xu} \mathrm{H}$. Optimization of preparation parameters for gentamicin-loaded PLLA nanoparticles and the drug release behavior in vitro. Sheng Wu Yi Xue Gong Cheng Xue Za Zhi 2009;26:351-5.

38. Gan LC, Hou SX, Bi YQ, Wang CG, Wang XC, Chen QX. Comparison of two preparation methods applied in tanshinone II(A)-loaded PLGA nanoparticles. Zhongguo Zhong Yao Za Zhi 2007;32:578-81.

39. Yuan XJ, Zhang ZR, Song QG, He Q. Research on thymopentin loaded oral N-trimethyl chitosan nanoparticles. Arch Pharm Res 2006;29:795-9.

40. Choisnard L, Geze A, Bigan M, Putaux JL, Wouessidjewe D. Efficient size control of amphiphilic cyclodextrin nanoparticles through a statistical mixture design methodology. J Pharm Pharm Sci 2005;8:593-601.

41. Attivi D, Wehrle P, Ubrich N, Damge C, Hoffman M, Maincent P. Formulation of insulin-loaded polymeric nanoparticles using response surface methodology. Drug Dev Ind Pharm 2005;31:179-89.

42. Bozkir A, Saka OM. Formulation and investigation of 5-FU nanoparticles with factorial design-based studies. Farmaco 2005;60:840-6.

43. Dhawan S, Kapil R, Singh B. Formulation development and systematic optimization of solid lipid nanoparticles of quercetin for improved brain delivery. J Pharm Pharmacol 2010. [In press].

44. Liu $\mathrm{CH}$, Wu CT, Fang JY. Characterization and formulation optimization of solid lipid nanoparticles in vitamin K1 delivery. Drug 2010;36:751-61.

45. Varshosaz J, Keihanfar M. Development and evaluation of sustained-release propranolol wax microspheres. J Microencapsul 2001;18:277-84.

46. Shah M, Pathak K. Development and statistical optimization of solid lipid nanoparticles of simvastatin by using 2(3) full-factorial design. AAPS PharmSciTech 2010;11:489-96.

47. Varshosaz J, Tabbakhian M, Mohammadi MY. Formulation and optimization of solid lipid nanoparticles of buspirone $\mathrm{HCl}$ for enhancement of its oral bioavailability. J Liposome Res 2010;20:286-96.

48. El-Gibaly I, Abdel-Ghaffar SK. Effect of hexacosanol on the characteristics of novel sustained-release allopurinol solid lipospheres (SLS): Factorial design application and product evaluation. Int J Pharm 2005;294:33-51. 
49. You $\mathrm{X}$, Wang $\mathrm{R}$, Tang $\mathrm{W}, \mathrm{Li} \mathrm{Y}, \mathrm{He} Z$, Hu H, Wu C. Selfmicroemulsifying drug delivery system of patchoulic alcohol to improve oral bioavailability in rats. Zhongguo 2010; 35:694-8.

50. Mahmoud EA, Bendas ER, Mohamed MI. Effect of formulation parameters on the preparation of superporous hydrogel selfnanoemulsifying drug delivery system (SNEDDS) of carvedilol. AAPS PharmSciTech 2010;11:221-5.

51. Basalious EB, Shawky N, Badr-Eldin SM. SNEDDS containing bioenhancers for improvement of dissolution and oral absorption of lacidipine. I: Development and optimization. Int J Pharm 2010;391:203-11.

52. Xiong Y, Liu QD, Lai L, Chen JH. Preparation of the oral selfmicroemulsifying drug delivery system of GBE50. Yao Xue Xue Bao 2009;44:803-8.

53. Zhu S, Hong M, Liu C, Pei Y. Application of Box-Behnken design in understanding the quality of genistein self-nanoemulsified drug delivery systems and optimizing its formulation. Pharm Dev Technol 2009;14:642-9.

54. Cui J, Yu B, Zhao Y, Zhu W, Li H, Lou H, Zhai G. Enhancement of oral absorption of curcumin by self-microemulsifying drug delivery systems. Int J Pharm 2009;371:148-55.

55. Liu Y, Zhang P, Feng N, Zhang X, Wu S, Zhao J. Optimization and in situ intestinal absorption of self-microemulsifying drug delivery system of oridonin. Int J Pharm 2009;365:136-42.

56. Zaghloul A, Khattab I, Nada A, Al-Saidan S. Preparation, characterization and optimization of probucol self-emulsified drug delivery system to enhance solubility and dissolution. Pharmazie 2008;63:654-60.

57. Zhang JY, Gan Y, Gan L, Zhu CL, Pan WS. [Optimization and evaluation of a new antischistosomal drug QH917 selfmicroemulsifying drug delivery system]. Yao Xue Xue Bao 2007;42:434-9.

58. Meng J, Zheng L. Application of mixture experimental design to simvastatin apparent solubility predictions in the microemulsifion formed by self-microemulsifying. Drug Dev Ind Pharm 2007;33:927-31.

59. Zidan AS, Sammour OA, Hammad MA, Megrab NA, Habib MJ, Khan MA. Quality by design: Understanding the formulation variables of a cyclosporine A self-nanoemulsified drug delivery systems by Box-Behnken design and desirability function. Int $\mathrm{J}$ Pharm 2007;332:55-63.

60. Patil P, Joshi P, Paradkar A. Effect of formulation variables on preparation and evaluation of gelled self-emulsifying drug delivery system (SEDDS) of ketoprofen. AAPS PharmSciTech 2004;5: e42.

61. Subramanian N, Ray S, Ghosal SK, Bhadra R, Moulik SP. Formulation design of self-microemulsifying drug delivery systems for improved oral bioavailability of celecoxib. Biol Pharm Bull 2004;27:1993-9.

62. Palamakula A, Nutan MT, Khan MA. Response surface methodology for optimization and characterization of limonenebased coenzyme Q10 self-nanoemulsified capsule dosage form. AAPS PharmSciTech 2004;5: e66.

63. Wang Y, Cong Z, Liu Q, Ling J, Zhou L. [Study on optimization of formulation and preparation process of sinomenine liposomes]. Zhongguo Zhong Yao Za Zhi 2009;34:275-8.

64. Mehanna MM, Elmaradny HA, Samaha MW. Ciprofloxacin liposomes as vesicular reservoirs for ocular delivery: Formulation, optimization, and in vitro characterization. Drug Dev Ind Pharm 2009;35:583-93.

65. Mura P, Capasso G, Maestrelli F, Furlanetto S. Optimization of formulation variables of benzocaine liposomes using experimental design. J Liposome Res 2008;18:113-25.

66. Gonzalez-Rodriguez ML, Barros LB, Palma J, GonzalezRodriguez PL, Rabasco AM. Application of statistica experimental design to study the formulation variables influencing the coating process of lidocaine liposomes. Int J Pharm 2007; 337:336-45.

67. Shivakumar HN, Patel PB, Desai BG, Ashok P, Arulmozhi $S$. Design and statistical optimization of glipizide loaded lipospheres using response surface methodology. Acta Pharm 2007; 57:269-85.

68. Solanki AB, Parikh JR, Parikh RH. Formulation and optimization of piroxicam proniosomes by 3-factor, 3-level Box-Behnken design. AAPS PharmSciTech 2007;8: E86.

69. Arulsudar N, Subramanian N, Muthy RS. Comparison of artificial neural network and multiple linear regression in the optimization of formulation parameters of leuprolide acetate loaded liposomes. J Pharm Pharm Sci 2005;8:243-58.

70. Zhong ZR, Liu J, Deng $Y$, Zhang ZR, Song QG, Wei $Y X$ He Q. Preparation and characterization of a novel nonviral gene transfer system: procationic-liposome-protamine-DNA complexes. Drug Deliv 2007;14:177-83.

71. Glogard C, Stensrud G, Hovland R, Fossheim SL, Klaveness J. Liposomes as carriers of amphiphilic gadolinium chelates: The effect of membrane composition on incorporation efficacy and in vitro relaxivity. Int J Pharm 2002;233:131-40.

72. Li X, Hu J, Zhao X, Hu H, Zhao Q, Chen D. [Preparation and stability of digalactosyl diglyceride as emulsifier for submicroemulsion]. Zhongguo Zhong Yao Za Zhi 2009;34:2172-6.

73. Gao Y, Wang Y, Ma Y, Yu A, Cai F, Shao W, Zhai G. Formulation optimization and in situ absorption in rat intestinal tract of quercetin-loaded microemulsion. Colloids Surf B Biointerfaces 2009;71:306-14.

74. Ambade KW, Jadhav SL, Gambhire MN, Kurmi SD, Kadam VJ, Jadhav KR. Formulation and evaluation of flurbiprofen microemulsion. Curr Drug Deliv 2008;5:32-41.

Source of Support: Nil, Conflict of Interest: None declared. Received: 31-12-10, Revised: 09-02-11, Accepted: 09-02-11

A free application to browse and search the journal's content is now available for Android based mobiles and devices. The application provides "Table of Contents" of the latest issues, which are stored on the device for future offline browsing. Internet connection is required to access the back issues and search facility. The application is compatible with all the versions of Android. The application can be downloaded from https://market.android.com/details?id=comm.app.medknow. For suggestions and comments do write back to us. 